\title{
Travel Demand Management: Lessons for Malaysia
}

\author{
Jeyapalan Kasipillai \& Pikkay Chan \\ Monash University Sunway Campus
}

\begin{abstract}
The growth in the number of motor vehicles has exacted costs on both the Malaysian economy and environment. For reasons such as increasing disposable incomes and poor management of the public transportation system, the number of vehicles has grown unabated and, in fact, is aided by various contradictory policy measures such as national car projects and the existence of fuel subsidies.

A phased, five-pronged Transport Development Management-based approach is recommended towards targeting a sustainable transportation system in Malaysia: (1) alteration of charges on road taxes and car insurance, (2) elimination of fuel subsidies, (3) imposition of fuel taxes and amendments in the bases for car taxation, (4) congestion charging, particularly in Kuala Lumpur, and (5) national road pricing. This move towards an eventual sustainable transportation system is presented for consideration.
\end{abstract}

\section{Introduction}

Malaysia has experienced tremendous economic success over the last three decades, with spill-over effects for its citizens in terms of increased disposable incomes and leisure time. A corollary of the "good life" is improved transportation. As in all countries worldwide, accessibility and mobility afforded by transportation are driven mainly by the growth in private car ownership. Correspondingly, the 
share for public transportation has fallen. In industrialized countries, car dependency is so deeply ingrained that, in the U.S. in particular, car ownership rates exceed an average of one car per licensed driver in many urban areas (Stopher 2004).

In Malaysia, as at the end of 2005, approximately 15 million vehicles (motor cars, motorcycles, taxis, buses and freight vehicles) plied Malaysian roads. Currently, the country has an adult population of about 15.1 million. Ninety percent of motor vehicles in Malaysia are privately-owned. As a developing country, the relatively cheaper motorcycle takes the largest share at 7 million (47\%), followed closely by passenger cars at 6.5 million (43\%) (Department of Statistics Malaysia 2006). From 2000 to 2005, the number of motorcycles and private passenger cars increased at an average rate of 4.5 percent and 10 percent, respectively. The future outlook is one of explosive growth, assuming no mitigating options are undertaken by the government and a "business as usual" scenario applies. According to Abidin et al. (2004), conservative projections place vehicle growth rates over the next 13 years at eight percent, with total vehicle numbers breaching 48 million by 2020 . Figure 1 illustrates the actual and projected upward surge in motor vehicle numbers.

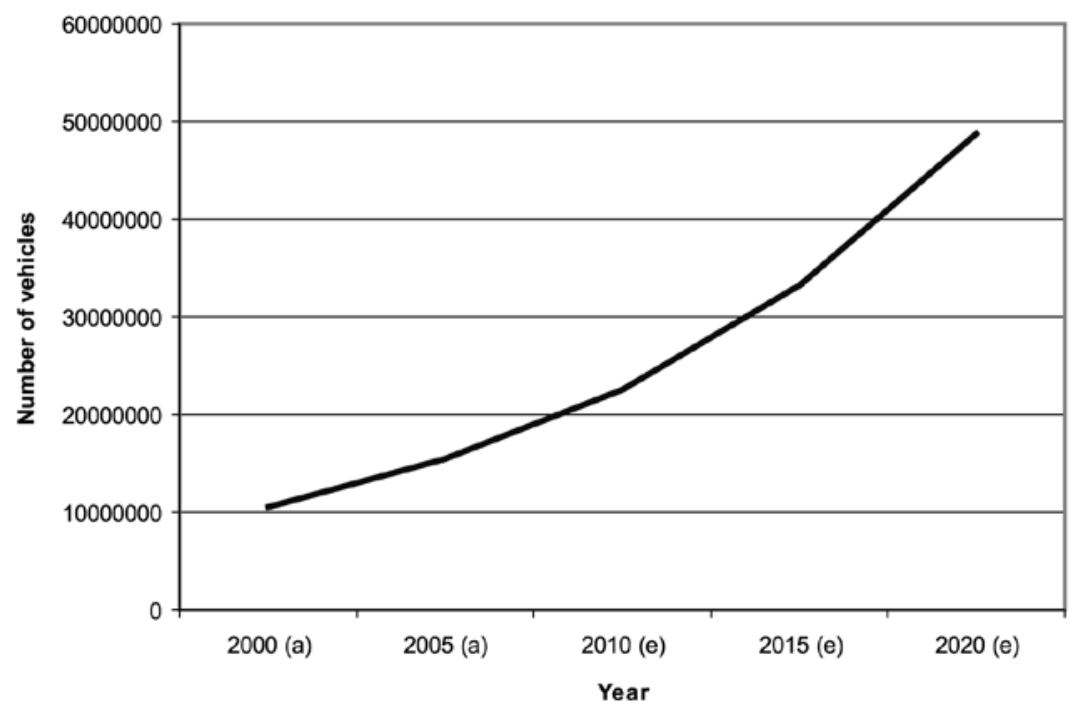

Note: $\mathrm{a}=$ actual, $\mathrm{e}=$ estimated

Source: Abidin et al. 2004 and Department of Statistics Malaysia 2006

Figure 1: Actual and Projected Number of Vehicles Malaysia (2000-2020) 


\section{Motor Vehicle Growth}

Many factors contribute to the growth in the number of vehicles in Malaysia, including increased population size and disposable incomes, fuel subsidies, and decentralization. Malaysia's national car projects also have played a role in motor vehicle growth by limiting the options available to the government.

\section{Increased Income and Demand for Transportation}

The Malaysian economy has recorded an average Gross Domestic Product (GDP) growth of six percent over the last 20 years (Asian Development Bank 2007). GDP per capita increased three-fold from USD 1,779 in 1980 to USD 5,239 (Econstats 2007; Department of Statistics Malaysia 2006).

A study by Dargay and Gately (1999) suggests a positive relationship between income and the demand for transportation, both freight and passenger, with the greatest growth in developing countries. This is particularly true in Malaysia, as increasing disposable income has made private motor vehicles more affordable, leading to increased demand (Pucher et al. 2005).

\section{Malaysia's National Car Projects}

As part of its pro-growth and heavy-industrialization strategy, Malaysia actively promoted its automobile industry. The country has two home-grown car manufacturing companies: National Automobile Enterprise Co. Ltd. (Perusahaan Otomobil Nasional Bhd, or Proton, as it is more commonly known) and Perodua (Perusahaan Otomobil Kedua Sdn Bhd) (Spencer and Madhaven 1989). Proton and Perodua together accounted for more than 90 percent of car sales since 2000 (Mohamad and Kiggundu 2007).

The government has supported both car manufacturing companies through various means, including protectionist policies. Imported vehicles in Malaysia are assigned 140 to 300 percent in excise duties to offer the two local carmakers a price advantage. With attractive pricing and protectionist policies, national cars are affordable to the public and have directly contributed to the increasing numbers of vehicles on the road. Given the Malaysian motor vehicle scenario, the government finds itself in the contradictory position of being involved in the car industry; measures to restrict private passenger car numbers would be akin to "shooting oneself in the foot."

\section{Fuel Subsidies}

Malaysia provides fuel subsidies for petroleum, diesel, gas and electricity. Direct subsidies totaled MYR 8.16 (USD 2.47) billion in 2005 before dropping slightly to 
MYR 7.30 (USD 2.14) billion in 2006 as the government reduced the subsidy. This decrease, however, has been reversed, as it is estimated that, with prices scaling USD 100 per barrel, subsidies for 2007 will balloon to MYR 12.2 (USD 3.70) billion. Prices at the pump are among the lowest in the region at MYR 1.92 (USD 0.58) per litre for petrol and MYR 1.58 (USD 0.48) per litre for diesel.

The fuel subsidy debate, including eventual reduction and elimination, has direct bearings on the transportation sector in Malaysia. The transportation sector accounts for 40 percent of the Malaysia's total energy consumption and is wholly dependent on fossil fuels (Abidin et al. 2004). The use of subsidies masks the real price of transportation; as it is, motor vehicle users do not pay the full cost of travel, including externalities such as environmental pollution, congestion, and accidents (Meyer et al. 1965). Such under-pricing has led to rapid motorization in Malaysia.

\section{Decentralization}

Decentralization is a double-edged sword in terms of motor vehicle usage. The trend towards decentralization accelerated from the 1990s, abetted by Malaysia's appetite for large-scale infrastructure investment with private-sector involvement, primarily in the construction of numerous expressways (Bunnell et al. 2002). One significant outcome of increased highway capacities is for homes and businesses to move further out of urban zones where land is both cheaper and more plentiful. This decentralization led to the same travel times, with longer distances but reduced congestion. A direct consequence was that car dependency increased as public transportation could not reach many of the outlying areas.

\section{Decreasing Public Transportation Usage}

The decline in public transportation usage coincided with the rise in the number of private motor vehicles, given the government's private-transport-driven policies. The capital city of Kuala Lumpur is serviced by four major bus fleets that run about 15,000 trips daily and by 24,721 licensed taxies. In 1998, the city's urban rail services were complemented by two light rail transit (LRT) systems and a monorail (Phang 2006).

Figure 2 illustrates that, even though an overall pattern of growth was seen in both LRT systems from 1998 to 2005, the rate of growth has slowed, especially from 2000 onwards. 


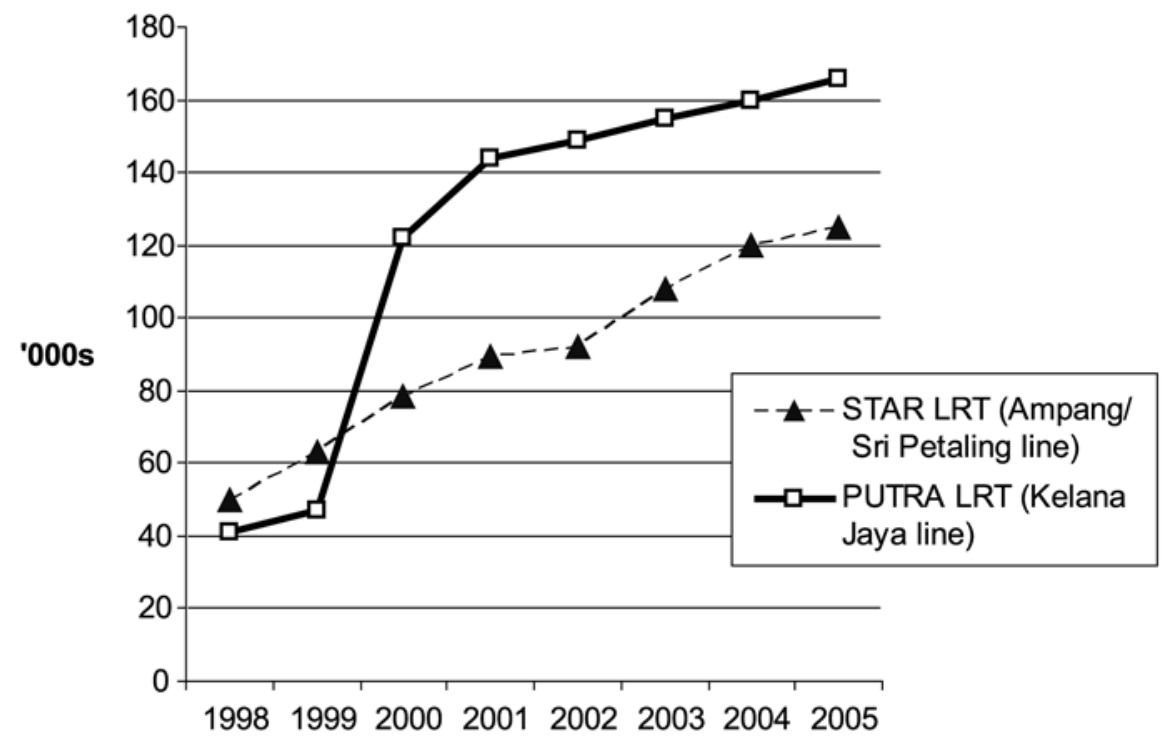

Source: Economic Planning Unit Malaysia 2006

\section{Figure 2: Average Daily Ridership (in 000s) on Urban Rail Services (1998 to 2005)}

The public has largely rejected public transportation as a viable mode of travel, as evidenced by a drastic drop in its usage rate in Kuala Lumpur from 35 percent in 1980 to only 16 percent in 2007 (Gakenheimer and Zegras 2004). This figure does not compare favorably with other Asian cities that have higher public transportation usage rates, including Seoul (60\%), Singapore (56\%), Manila (54\%), Tokyo (49\%), and Bangkok (30\%), and is an indictment against the ambiguous policies set for the transportation sector in the country (Abdul-Aziz 2006).

\section{Government's Response to Vehicle Growth}

The various documented negative effects of the growth in the number of motor vehicle include traffic congestion leading to wasted driver and passenger time and their associated costs; increased fuel consumption; air and noise pollution; and elevated accident and fatality rates. In Malaysia, there are also socio-political issues of eviction of poor urban residents to make way for infrastructure development. Given such negative outcomes, the government has given only a lukewarm 
response to unabated vehicular growth by introducing legislative measures to combat unwarranted abuse of the environment; in particular the implementation of emission standards and inspection and maintenance systems. Measures such as switching to natural gas fuels in the short term and bio-fuels in the long term also were implemented within the frameworks of two national-level fuel policies: the Five-Fuels Diversification Policy in 1999 and the National Bio-Fuel Policy in 2006. The Five-Fuels Diversification policy acknowledged biomass as a source of energy in addition to the traditional fuels of oil, natural gas, hydropower, and coal, whereas the National Bio-Fuel Policy took this initiative a step further by giving credence to bio-fuels (especially bio-diesels) as viable alternative sources of energy. Malaysia has a competitive advantage as the world's leading palm oil producer, as one form of bio-diesel is derived from processed palm oil (Economic Planning Unit 2006).

A point to note is that, in the midst of such government initiatives, there are still no direct policies to tackle demand for transportation at the source, except for the existence of privatized tolled highways. Malaysia practices a variant of road pricing in the form of tolled roads, the first of which was in 1978 on the North-South Expressway (Johansen 1989). However, toll charges in Malaysia were not explicitly implemented to internalize external costs such as congestion but reportedly to recover infrastructural costs. The Malaysian government set up a lease-like mechanism (known as Build-Operate-Transfer) wherein private concessionaires finance, design, build, and maintain roads in exchange for exclusive rights to impose tolls upon entry and exit within a time limit. Upon expiration of this time limit, ownership of the roads reverts to the government, and the roads, presumably, become toll-free. Despite spiraling toll charges, which are increasing on average by 10 percent every three years, the number of vehicle continues to grow by a conservative estimate of eight percent annually (Abidin et al. 2004).

\section{Agenda for Reform: A Five-Pronged Transportation Approach}

Given the trends seen over the past decades as Malaysians continued to sink ever deeper into automobile dependency, the negative effects of high vehicle usage outweighed the benefits of accessibility and mobility. This situation prompted the government to explore alternative measures practiced elsewhere for domestic adoption. There was an urgent need for bold policy initiatives by the government to address some of the negative effects of the surge in private transportation in Malaysia. In this regard, the government undertook a National Transport Policy 
and Strategy Study in 2003, which dealt with land-based public transportation. The study probed into the need for a comprehensive transportation plan, particularly for urban areas. Major projects since completion of the study were, however, still skewed towards private car usage and include ITIS (Integrated Transport Information System), in which private motorists were provided real-time traffic information to plan their journeys effectively, as well as the SMART (Stormwater Management and Road Tunnel) system, which provides the dual purpose of traffic alleviation and flash-flood management (Economic Planning Unit Malaysia 2006). The SMART system is a dual drainage and road structure located in Kuala Lumpur. The principal aim of this tunnel is to overcome the incidence of flash floods and reduce traffic jams during peak hours. The motorway tunnel, which is $4 \mathrm{~km}$ long, was opened for public use in May 2007; the stormwater section began operations in June 2007. Motorists incur MYR 2 for each trip for the use of the motorwater tunnel and save approximately 30 minutes of travel time.

Given the background of the transportation system in Malaysia, a five-pronged approach is recommended towards targeting a sustainable transportation system in Malaysia:

1) alteration of charges on road taxes and car insurance

2) elimination of fuel subsidies

3) imposition of fuel taxes and amendments in the bases for car taxation

4) congestion charging, particularly in Kuala Lumpur

5) national road pricing

All these approaches come within the ambit of Travel Demand Management (TDM) programs aiming collectively to encourage more efficient use of transport resources such as road and parking spaces as well as vehicle capacity and energy use. This is achieved by implementing strategies to improve transport options and achieve accessible and efficient use of land and various other planning reform and support programs (Meyer 1997; Litman 2003).

Effective TDM measures implemented in the early stages of development can avoid the problems that result from heavy reliance on private transportation. Granted that Malaysia is only 12 years away from its self-imposed deadline of Developed Nation status in 2020 and with unmitigated vehicular growth thus far, TDM can help mould the country's economic, social, and environmental development towards more sustainable levels (Gwilliam et al. 2004). 


\section{Altering Charges on Road Taxes and Car Insurance}

Transportation as a good is essentially under-priced; 32 percent of the total costs of automobile use are external costs (e.g., pollution) and are paid not by drivers but by society. Twenty-four percent constitute internal fixed costs (e.g., depreciation) that are not affected by driving distances (Litman 2007).

A pertinent point to be made in quantifying costs associated with automobile usage is that consumers frequently underestimate the cost of running cars by considering only ownership and operating costs without considering other associated external costs (Gardner and Abraham 2006).

A starting point in the way individual perception of road user charging can be altered prior to the imposition of congestion charging involves road tax and car insurance. Altering the charging of both road tax and car insurance from a fixed yearly cost to a per-journey payment is a way of applying the Polluter Pays Principle (PPP). On the face of it, given millions of vehicles on the road, this step is an administratively tedious task, but the government already has the infrastructure in place for its implementation: odometer audits via its inspection and maintenance network or full electronic payment schemes such as those currently partially implemented for tolled roads.

In an article "Ministry looking into cross-subsidy to keep fuel prices down" (The Star, November 11, 2007), it was reported that the government-proposed increasing road tax charges for luxury high-powered vehicles. However, a serious shortcoming of this proposal is that it is still a flat charge that does not address the issue of distance traveled. In fact, flat charges encourage greater usage as, psychologically, users want to lower the per-unit cost of travel. Such actions will inevitably defeat the purpose of lowering travel demand.

\section{Elimination of Fuel Subsidies}

A gradual reduction in and ultimate elimination of fuel subsidies should result in monies that can be channeled towards improving the reach and connectivity of public transportation networks and subsidies for the cost of public transportation fares. This was, in fact, an approach purportedly taken by the government as prices at the pump, which are determined by the government, have increased by approximately 40 percent since 2004 as subsidies were reduced twice, once in 2005 and again in 2006. Given no further reductions in the subsidy and compounded with recent peaks in fuel prices, it is extremely unlikely the subsidy bill will come 
down. One obvious negative effect of fuel subsidies is the diversion of resources away from other development initiatives.

A suggestion is made for the reduction to be fine-tuned further by first lowering the subsidies at the pumps, leaving the subsidies for the other sectors of the economy intact. The initial savings can be channeled towards the public transportation agenda, effectively leaving out issues of cross-subsidies of other sectors of the economy. A matter that has to be reiterated is that public transportation services must be enhanced prior to reducing the demand for private cars via various traffic restraint programs to avoid a political and public backlash. Thus, fuel subsidies can be used for continuous enhancement of the public transportation system after the government has provided adequate initial support.

In the longer term, it is clear that subsidies should be gradually eliminated, as their associated costs, including regulatory and compliance costs on the part of the government and distortions created in the economy, are disproportionately high compared to the benefits garnered. The fuel subsidy mentality dents competitiveness and encourages a consumption ethic (The Oxford Business Group 2006). Subsidies discourage more efficient usage of fuel and the search for alternative fuels, thereby fostering an attitude of fossil fuel dependency. As a component of total car operating cost, fuel prices are a strong signal to alter consumption behavior in the long run (Ribeiro et al. 2007). The conclusion is that Malaysia has been pampering its consumers of fossil fuels by not only allowing market forces to determine fuel prices, but by also compounding the situation with fuel subsidies.

\section{Fuel and Car Taxes: A Necessary Evil?}

In the long run, fuel taxes encourage a conservation ethic, leading to prudent energy management, greater economic efficiency, and lower pollution emissions (Litman 2007). Fuel taxes should be differentiated based on the amount of carbon, for example, to encourage use of "cleaner fuels." To make fuel taxes more acceptable to the public, they must be hypothecated; that is, the revenue must be spent on infrastructural improvements or on public transportation.

Another tax initiative is managing within the existing framework where there is already a comprehensive system of car taxation via excise and import duties as well as sales taxes executed by the Royal Customs and Excise Duties Department Malaysia. An avenue exists for penalizing negative and rewarding positive environmental behaviors within the current system with minimal changeover and implementation costs. A revenue-neutral system can be implemented relatively 
easily, in which fuel-efficient, low-emission cars are taxed at lower rates while fuelguzzling, high-emission cars are imposed high tax rates. Changing the relative prices of different cars using an environmental benchmark would send strong signals to the market to provide incentives to both the purchasers and manufacturers of environmentally-friendly cars.

\section{Congestion Charging in Urban Zones}

Road pricing means that motorists pay directly for the privilege of driving on a particular road or in a particular area (Victoria Transport Policy Institute 2007). Congestion pricing is a particular type of road pricing where variable fees are charged with an explicit purpose to reduce congestion (Litman 2007a). Congestion charging in urban zones such as the capital city of Kuala Lumpur should be given serious thought, given that no travel demand measures have been implemented since recommendations were made more than three decades ago by the capital city's local government.

The central business district of Kuala Lumpur experiences the highest level of traffic congestion in Malaysia. According to the report "Malaysia's capital mulls traffic fees to cut congestion" (AFX News Ltd, November 10, 2007), about 2 million cars enter into the city centre daily, with traffic growth of between 10 to 15 percent every year. In an early attempt to manage congestion levels, the Kuala Lumpur City Hall contemplated implementing an Area Licensing Scheme (ALS) in 1976, similar to the scheme established in Singapore. The ALS was introduced by the Singapore government in June 1975 with the primary objective of lowering traffic congestion during the peak hours. However, after installing 13 steel gantries at various strategic points within the city limits, a Malaysian Cabinet decision in 1979 halted its full implementation. Three grounds for the rejection were given, including an inadequate public transportation system; inadequate park-and-ride facilities for those wishing a shift from passenger car to public transportation; and the non-existence of an alternative route rimming the ALS boundary to allow traffic to flow without crossing the central business district (Mohamad and Kiggindu 2007).

In September 2007, Kuala Lumpur's mayor resurrected the idea of congestion charging for the capital city, using the successful implementation in London and Stockholm as precedents. However, no other details were forthcoming regarding the timing or pricing of the charge. Operationally, it is observed that, with the ITIS in place, implementing the area-wide congestion charge is fairly easy. 
Care should be taken, however, in transplanting the London experience wholesale to Kuala Lumpur. London's city centre was experiencing severe congestion, parking charges were extremely high, and, well before congestion charging was implemented, a well-managed and efficient public transportation system encompassing bus, transit, subway, rail, and taxi services was already in place (Washbrook et al. 2006). In contrast, travel speed during congestion in Kuala Lumpur is still relatively acceptable compared to other Asian cities such as Bangkok and Jakarta. Free or low-cost parking spaces are available in many parts of Kuala Lumpur due to pressure from a strong pro-business lobby. Finally, public transportation in Kuala Lumpur is relatively less well-managed and efficient than in London.

A large part of the congestion charging issue would naturally center on issues of pricing. A study by Nor and Nor (2006) found that in the new administrative capital of Putrajaya, penalties ranging from MYR 3 (USD 0.88) for motorcycles to MYR 28 (USD 8.24) for private cars, differentiated by the nature of travel (business, social, or tourism purposes), would have to be imposed to deter private transportation usage.

Malaysia needs to learn from the experience of countries that have implemented congestion charging but localize the process to suit local conditions. In particular, public acceptance, viable alternative travel modes, and the hypothecation of revenue are vital ingredients to make congestion charging successful.

\section{National Road Pricing}

One policy direction that should be seriously contemplated by the government includes road pricing on a national basis as a way for charging for external costs such as congestion, accidents, and environmental impacts. It is generally accepted that, in line with Pigouvian principles, road pricing should be based on marginal costing principles. In the UK, the government has argued that, in the long run, marginal cost is equivalent to fully-allocated cost, where capital costs were included but congestion was not (Nash 2007). While a full discussion of the theoretical debates surrounding this issue is beyond the scope of this paper, road pricing differentiated on fuel efficiency can be used to influence market behavior. For example, alternative-fuel vehicles can get a lower kilometerage charge, while heavy fuel consumers can be penalized.

To make road pricing more palatable to the public, the revenue raised from road pricing charges can be channelled towards further research into more environmentally-friendly vehicles in terms of fuel efficiency and emissions level as well as 
improvements in the public transportation system. On an individual level, road pricing monies can even be used to provide financial incentives to individuals to buy environmentally-friendly vehicles which would in turn encourage manufacturers to move into developing greener auto technology. Initially, simple distance charges differentiated on engine capacity can be introduced. Simple distance charges do not require sophisticated technological support and can be introduced relatively quickly and easily. In the long term, to further influence travel behavior, road pricing also can be differentiated based on the time of day, distance travelled, congestion levels, and location. However, this would require Global Position System (GPS) antennas as well as accompanying hardware and software, which are still prohibitively expensive. However, given time and with the gradual reduction in prices in technological gadgets, road pricing can be implemented relatively easily and is one of the safest bets in tackling the issue of car use and its associated negative aspects.

\section{Conclusion}

It is evident that government policies still encourage private car ownership when a longer-term view should be taken, especially the logical inference that there is a physical upper limit to the number of cars that roads can take. To change the policy slant towards that of sustainable transportation, especially in de-emphasizing the car and conversely emphasizing public transportation, would require tremendous political will and public acceptance.

A phased introduction towards sustainable transportation using the recommended TDM-based, five-pronged approach is strongly advised. The spirit of current initiatives towards cleaner vehicles and fuels could be retained and further enhanced by the encouragement of a shift to shorter and more efficient trips as well as travel by more environmentally-friendly forms of transportation.

A gradual, incremental implementation starting with the way road tax and car insurance are charged is preferred, as opposed to a "big bang" approach of a full-on system. Motorists would be given time to adjust to the idea of eventual full accountability for the cost of travel. Technology and policy needs constantly evolve and, over the longer term, a regime change towards full travel demand management via national road pricing is possible.

The payoffs are spectacular and run the gamut from environmental to economic gains, including reduced traffic congestion, road and parking facility cost savings, reduced accident and fatality rates and decreased pollution emission levels. 


\section{References}

Abdul-Aziz, A.R. 2006. Privatisation of fixed-rail transit systems: A case study of Malaysia's STAR and PUTRA. Canadian Journal of Civil Engineering 33(7): 846853.

Abidin, A.Z., H. Mansor, R.D.R. Ahmad, R. Abdullah, and I. Chung. 2004. The estimation of carbon dioxide emissions from the transport sector in Malaysia (2000 - 2020) for National Institute for Environmental Studies 9th Asian Pacific Integrated Model (AIM) Workshop. Kuala Lumpur, Malaysia. Accessible at: http://www-iam.nies.go.jp/aim/AIM_workshop/9thAIM/Session6/ AIM-Mar'04.pdf. Accessed November 10, 2007.

Bunnell, T., P.A. Barter, and S. Morshidi. 2002. City profile Kuala Lumpur Metropolitan Area: A globalising city-region. Cities 19(5): 357-370.

Dargay, J., and D. Gately. 1999. Income's effect on car and vehicle ownership, worldwide:1960-2015. Transportation Research Part A: Policy and Practice 33 (2): 101-138.

Department of Statistics Malaysia. 2006. Compendium of Environment Statistics: Malaysia 2006. Putrajaya, Malaysia: Percetakan Nasional Malaysia Bhd.

Economic Planning Unit Malaysia. (2006). Ninth Malaysia Plan 2006-2010. Putrajaya Malaysia: Economic Planning Unit. Accessible at: http://epu.jpm/my/ MYR9/html. Accessed November 21, 2007.

Gakenheimer, R., and C. Zegras. 2004. Sustainable Mobility Project (SMP), 2004 drivers of travel demand in cities of the developing world: A synthesis of eight case studies. Geneva, Switzerland. World Business Council for Sustainable Development (WBCSD). Accessible at: $h t t p: / / w w w . w b c s d . o r g / w e b / p u b l i c a-$ tions/mobility/mobility-appendix.pdf. Accessed November 15, 2007.

Gardner, B., and C. Abraham. 2006. What drives car use? A grounded theory analysis of commuters' reasons for driving. Transportation Research Part F 10(2007): 87-200.

Gwilliam, K., K. Kojima, and T. Johnson. 2004. Reducing air pollution from urban transport. The World Bank. Accessible at: http://www.airimpacts.org/documents/local/ReducingAirPollutionUrbanTransport.pdf. Accessed November 27, 2007. 
Johansen, F. 1989. Toll road characteristics and toll road experience in selected South East Asia countries. Transportation Research Part A: General 23(6): 463-466.

Litman, T. A. 2003. The online TDM Encyclopedia: Mobility Management Information Gateway. Transport Policy 10(3): 245-249.

Litman, T.A. 2007. Evaluating rail transit benefits: A comment. Transport Policy 14 (2007): 94-97.

Litman. T.A. (2007a). Win-win transportation solutions: Mobility management strategies that provide economic, social and environmental benefits. Victo-

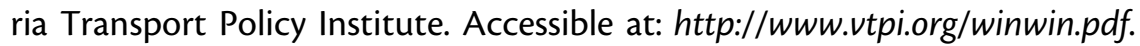
Accessed November 25, 2007.

Meyer, J., J. Kain, and M. Wohl. 1965. The Urban Transportation Problem. Cambridge, USA: Harvard University Press.

Meyer, M. 1997. A Toolbox for Alleviating Traffic Congestion and Enhancing Mobility. Washington DC: Institute of Transportation Engineers.

Mohamad, J., and A.T. Kiggundu. 2007. The rise of the private car in Kuala Lumpur, Malaysia: Assessing the policy options. IATSS Research 31(1): 69-77.

Nash, C. 2007. Road pricing in Britain. Journal of Transport Economics and Policy 41(1): 135-147.

Nor, N.G., and A.R. Nor. 2006. Predicting the impact of demand - and supply-side measures on bus ridership in Putrajaya, Malaysia. Journal of Public Transportation 9(5): 57-70.

Oxford Business Group. 2006. Emerging Malaysia 2006. Oxford Business Group. Accessible at: $h t t p: / / b o o k s . g o o g l e . c o m / b o o k s ? i d=o p M L i p E W V O 0 C \& p g=R A 2-$ $P A 106 \& l p g=R A 2-P A 106 \& d q=$ fuel + subsidy + malaysia $+2006 \&$ source $=$ we $b \&$ ots $=B H t$ thoNHrC\&sig=e-eOw7cOv8yB2Aqukgce6cZR_II\#PRA2-PA107,M1. Accessed October 25, 2007.

Phang, S.Y. 2006. Urban rail transit PPPs: Risk assessment of recent strategies. First International Conference on Funding Transportation Infrastructure, Canada. Accessible at: $h t t p: / / w w w . u o f a w e b . u a l b e r t a . c a / i p e / p d f s / T r a n s p o r t P a p e r-$ Phang.pdf. 
Pucher, J., H. Park, and M.H. Kim. 2006 Public transport reforms in Seoul: Innovations motivated by funding crisis. Journal of Public Transportation 8(5): 4162.

Riberio, S.K., S. Kobayashi, M. Beuthe, J. Gasca, D.S. Lee, Y. Muromachi, D.J. Newton, S. Plotkin, D. Sperling, R. Wit, and P.J. Zhou. 2007. Transportation and its infrastructure. In B. Metz, O.R. Davison, P.R. Bosch, R.M. Dave \& L.A.Meyer (Eds.), Climate Change 2007: Mitigation. Contribution of Woking Group III to the Fourth Assessment Report of the Intergovernmental Panel on Climate Change. Cambridge, UK and New York, USA: Cambridge University Press.

Spencer, A.H., and S. Madhavan. 1989. The car in South-east Asia. Transportation Research A 23(A): 425-437.

Stopher, P.R. 2004. Reducing road congestion: a reality check. Transport Policy 11: pp.117-131.

Victoria Transport Policy Institute. 2007. Road pricing: Congestion pricing, value pricing, toll roads and HOT lanes. Online TDM Encyclopedia. Accessed at http://www.vtpi.org/tdm/tdm35.htm. Accessed October 31, 2007.

Washbrook, K., W. Haider, and M. Jaccard. 2006. Estimating commuter mode choice: A discrete choice analysis of road pricing and parking charges. Transportation 33: 621-639.

\section{About the Authors}

Jeyapalan Kasipillai (jeyapalan@buseco.monash.edu.my) is a Professor and Chair of the Malaysian Business Unit at Monash University Sunway Campus. He completed his doctoral thesis at the University of New England, Australia and master's degree at the University of Stirling, Scotland. He is a fellow member of both the UK Chartered Institute of Secretaries and the Malaysian Institute of Taxation, a member of the Editorial Committee of e-Journal of Tax Research, Australia, and was appointed by Tax Notes International, Fairfax, USA in 2004 to be its official correspondent for Malaysia.

Pikkay Chan (Iam.pik.kay@buseco.monash.edu.my) is a Graduate Research Assistant at the Malaysian Business Unit (MBU) of the School of Business, Monash University Sunway Campus Malaysia. She is a graduate of the Association of Chartered Certified Accountants, UK and holds a Master in Computing from the University of Kent. UK. 